\title{
Demystifying Cultural Differences in Country-of-Origin Effects: Exploring the Moderating Roles of Product Type, Consumption Context and Involvement
}

\author{
Piyush Sharma ${ }^{1}$
}

\begin{abstract}
This paper explains mixed findings about the differences in country-of-origin effects for different product categories and cultures by hypothesizing interactions between three product characteristics and six personal cultural orientations. Using a web-based study with 1568 consumers in four countries (China, India, UK, and USA), it shows that product type (hedonic vs. utilitarian) moderates the influence of individualism-collectivism and long vs. short-term orientation; consumption context (private vs. public) moderates the influence of power distance and masculinity-femininity; and product involvement moderates the influence of uncertainty avoidance, on product evaluations and behavioral intentions.
\end{abstract}

Keywords: Country-of-origin, culture, individualism-collectivism, power distance, uncertainty avoidance, masculinity-femininity, long-term orientation

\footnotetext{
${ }^{1}$ Dr. Piyush Sharma, Associate Professor Department of Management and Marketing The Hong Kong Polytechnic University Hung Hom, Kowloon, Hong Kong Phone: +852-2766-7367; Fax: +852-2765-0611

Email:mspiyush@inet.polyu.edu.hk
} 


\section{Demystifying Cultural Differences in Country-of-Origin Effects: Exploring the Moderating Roles of Product Type, Consumption Context and Involvement}

\section{INTRODUCTION}

Prior research on country-of-origin (COO) effects shows that products made in developed countries are perceived to be of higher quality compared to those made in less developed countries (Häubl and Elrod, 1999; Papadopoulos et al., 1990; Russell and Russell, 2006; Verlegh et al., 2005). However, recent research questions the relevance and generalizability of COO effects across diverse consumer segments and product categories (Usunier and Cestre, 2008; Josiassen and Harzing, 2008). Moreover, despite growing evidence about the influence of culture on consumer behavior, there is little research on cross-cultural differences in $\mathrm{COO}$ effects and it shows mixed results (Usunier and Cestre, 2007).

For example, Gürhan-Canli \& Maheswaran (2000) show that consumers from a collectivistic culture (e.g., Japan) evaluate a domestic product (mountain bike) more favorably regardless of product superiority; and those from individualistic cultures (e.g., USA) evaluate a domestic product more favorably only when its quality is better than the imported product. On the other hand, some consumers from collectivistic cultures (e.g., China and India) prefer imported luxury products (e.g., cars, watches, and clothing) to enhance their social status (Cui and Liu, 2001; Batra et al., 2000); whereas others believe that domestic products offer similar value as the imported products for cars, watches, and household appliances (Kinra, 2006).

Similarly, compared to consumers from high uncertainty avoidance cultures, those from low uncertainty avoidance cultures have less favorable evaluations and behavioral intentions towards imported products with high personal uncertainty (Lee et al., 2007); and consumers from high masculine cultures (e.g., Japan) show a stronger influence of COO image on attitudes 
towards imported products (Knight and Calantone, 2000). Interestingly, these studies assume national culture to have a significant influence; whereas others find resistance to foreign products only when the cultural identity is salient (Russell and Russell, 2006).

Many studies show differences in $\mathrm{COO}$ effects on consumers from different countries, based on generic product class (Kaynak and Cavusgil, 1983; Roth and Romeo, 1992), product attributes (Chryssochoidis et al., 2007; Leonidou et al., 2007), product type (Chattalas et al., 2008; Leclerc et al., 1994; Balabanis and Diamantopoulos, 2004), consumption context (Hu et al., 2008; Piron, 2000), involvement (Lee et al., 2005; Gürhan-Canli and Maheswaran, 2000; Ahmed et al., 2004; Josiassen et al., 2008; Verlegh et al., 2005; Lin and Chen, 2006), and product-country image congruence (Bhaskaran and Sukumaran, 2007). However, they do not explore the influence of culture as a possible reason for these differences.

To summarize, there is little clarity about cross-cultural differences in the $\mathrm{COO}$ effects across different product categories because of several reasons. First, most research in this area explores the influence of one cultural factor (i.e., collectivism or COL) and ignores other factors such as individualism (IND), power distance (PDI), uncertainty avoidance (UAI), masculinityfemininity (MAS), and long vs. short-term orientation (LTO). Second, many studies use the scores for different countries based on Hofstede's (2001) national cultural dimensions rather than operationalize personal cultural orientations at individual consumer level. Third, very few studies examine the interaction between personal cultural orientations and product characteristics.

This paper addresses all these gaps with a conceptual framework incorporating six personal cultural orientations (individualism, collectivism, power distance, uncertainty avoidance, masculinity-femininity, and long- vs. short-term orientation) and three product characteristics (product type, consumption context, and product involvement) to hypothesize 
several differences in the interaction between these variables. Moreover, it uses self-reported personal cultural orientations at individual level to operationalize culture (e.g., Triandis and Gelfand, 1998; Donthu and Yoo, 1998), rather than the national scores for Hofstede's dimensions. Findings from a web-based study of 1568 consumers in four countries (China, India, UK, and USA) across eight product categories support all the hypotheses.

Thus, by exploring the interaction between culture and product categories, this paper provides useful insights into the cross-cultural differences in COO effects, which may help in developing more effective international marketing strategies (Alden et al., 2006; Douglas and Craig, 1997; Steenkamp and Ter Hofstede, 2002; Strizhakova et al., 2008; Russell and Russell, 2006). It also helps explain several mixed findings reported in prior research. Next, this paper discusses the theoretical background of this research, develops its conceptual framework and hypotheses, and describes the web-based study used to test the hypotheses. Finally, it discusses the implications of its findings along with some limitations and directions for future research.

\section{THEORETICAL BACKGROUND}

Prior research on $\mathrm{COO}$ effects uses several theoretical perspectives. The information processing perspective argues that $\mathrm{COO}$ is an intangible product attribute similar to extrinsic cues (e.g., price, brand, and warranty) but different from intrinsic (e.g., taste, design, and other product features) cues; and it affects product evaluations through "Halo" and "Summary" effects (Han, 1989). Under the halo effect, consumers evaluate the products based on their COO image; whereas under the summary effect consumers first make abstractions of the product information into a country image, which then directly affects their product evaluations.

COO is not merely a cognitive cue; it also has a symbolic and emotional meaning for consumers (Hong and Wyer, 1989, 1990). It may associate a product with status, authenticity and 
exoticness; link a product to a rich product-country imagery with sensory, affective and ritual connotations; and relate a product to a sense of national identity and pride leading to a strong emotional attachment (Verlegh and Steenkamp, 1999). In other words, COO may act as an affect-laden, "value-expressive" or "self-image" attribute (Batra et al., 2000).

COO also has normative associations wherein consumers perceive the evaluation of products from a certain country as an endorsement of its policies, practices, and actions (Leonidou et al., 2007). Thus, consumers punish some countries by boycotting and reward others by buying their products (Smith, 1993). Consumer ethnocentrism (CET) is another salient norm of $\mathrm{COO}$ effects, which relates to the inclination to favor domestic products based on judgments of the morality of purchasing foreign-made goods (Shimp and Sharma, 1987). Consumer animosity is a similar construct, defined as the remnants of antipathy related to historical enmity, which may affect consumers' attitudes towards products from a specific country (Klein, 2002).

COO effects are also influenced by the social, financial, and performance dimensions of perceived risk (Ahmed et al., 2002). Consumers may spend more time and effort to evaluate the attributes and performance of products made in countries with high perceived risk; have unfavorable attitudes and lower purchase intentions for such products; and associate them with greater perceived risk (Verlegh and Steenkamp, 1999). Similarly, consumer knowledge, familiarity, and experience (Schaefer, 1997), and involvement (Johansson et al., 1994; Ahmed et al., 2004; Lee et al., 2005) with the product category or the brand also influence COO effects. COO effects vary from one country to another, due to differences in economic, sociocultural, political-legal, and other factors (Leonidou et al., 2007). Attitudes towards products made in a specific country also vary over time and across product categories, based on consumer perceptions about its degree of marketing sophistication and manufacturing infrastructure 
(Chryssochoidis et al., 2007). Others use culturally-influenced differences in reasoning processes between Chinese and Americans to explain the differences in $\mathrm{COO}$ effects between consumers in Hong Kong and USA (Malhotra and McCort, 2001).

Buying and possession of imported products may also signal higher levels of material success for the consumers in emerging markets and help them make a positive impression on others (Hu et al., 2008; Sharma, 2009). The symbolic value of foreign-made products may explain their higher popularity in the emerging markets such as China (Zhou and Hui, 2003; Wang and Yang, 2008), India (Batra et al., 2000; Kinra, 2006), Eastern Europe (Manrai et al., 2001; Huddleston et al., 2001), and Latin America (Almonte et al., 1995). However, most of these emerging markets are also collectivistic cultures (Hofstede, 2001), which others associate with more favorable evaluations of domestic products regardless of their quality compared to imported products (Gurhan-Canli and Maheswaran, 2000); and higher consumer ethnocentrism reflecting negative socio-normative beliefs about purchasing foreign-made products (Yoo and Donthu, 2005). Hence, there is no consensus about the nature and extent of culture's influence on COO effects.

\section{CONCEPTUAL FRAMEWORK AND HYPOTHESES}

\section{Product Type (PT) - Hedonic versus Utilitarian}

Consumers purchase and consume hedonic products to satisfy their desires for sensory pleasure and their symbolic needs related to their sense of themselves and others' perceptions of them; in contrast, they use utilitarian products to satisfy practical or functional needs, and to solve consumption-related problems (Holbrook and Hirschman, 1982). Hedonic goods (e.g., flowers, designer clothes, music, luxury watches, sports cars, and chocolates) are multi-sensory and provide experiential consumption for fun, pleasure, and excitement; in contrast, utilitarian 
goods (e.g., household appliances, detergents, and personal computers) are more instrumental and mostly provide functional utility (Dhar and Wertenbroch, 2000). The evaluation process for utilitarian products tends to be cognitively driven, hence consumers are more likely to focus on the objective and tangible product attributes; whereas they evaluate hedonic products based on aesthetics, taste and sensory experience, rather than on tangible attributes (Holbrook and Moore, 1981). Thus, the evaluation process for hedonic products seems more subjective and affectdriven compared to the relatively more cognitive evaluation process for utilitarian products.

Prior research on the differences in $\mathrm{COO}$ effects between hedonic and utilitarian products shows that consumers associate these products with different countries of origin, such as hedonic products (nail polish and fragrance) with France or Spain, and utilitarian products (foil wrap and gasoline) with Germany or Japan (Leclerc et al., 1994). Others show a higher preference for imported products in hedonic vs. utilitarian product categories in general (Piron, 2000). However, most of the other studies do not specifically distinguish between hedonic vs. utilitarian categories; hence it is unclear how product type may affect $\mathrm{COO}$ effects.

The influence of culture on preference for hedonic vs. utilitarian products uses the notion of cultural conditioning, which is defined as the influence of cultural values on attitudes and preferences towards marketing stimuli (Hirschman, 1986). According to this view, consumers prefer culturally conditioned stimuli over other options, even if it is not the best available alternative. This explains the relatively higher preference for hedonic choices among consumers in Western countries with individualistic cultures and utilitarian choices among consumers in countries with collectivistic cultures (Arnold and Reynolds, 2003; Holt, 1995).

With recent economic progress, consumption in many emerging markets is also shifting from utilitarian to relatively more hedonic (Tse et al., 1989; Batra, 1997; Cui and Liu, 2001). 
However, most emerging markets are also collectivistic cultures (e.g., India and China) with a strong sense of responsibility to the social groups rather than the individual, hence many consumers in these markets may be culturally conditioned towards utilitarian consumption (Lim and Ang, 2008). For example, most Chinese consumers rely on facts rather than feelings when making purchase decisions (Levy, 1996); and due to their deep-seated values of thrift and frugality they tend to make purchase decisions based on a product's functional benefits (Tse, 1996). Chinese ads tend to use utilitarian appeals, implying that the Chinese consumers may prefer utilitarian and functional values rather than hedonism (Pollay et al., 1990; Tse et al., 1989). In fact, Chinese consumers also rate utilitarian products as more sophisticated, competent, exciting, and sincere than hedonic products (Lim and Ang, 2008).

Individualism also relates with values such as power, achievement, and hedonism; and collectivism with benevolence, tradition, and conformity (Schwartz et al., 2001). Hence, in the context of $\mathrm{COO}$ effects, the consumers with collectivistic orientation may focus on the utilitarian aspects of imported products and hence associate a positive country image with the quality of utilitarian products to a greater extent compared to hedonic products. In contrast, consumers with individualistic orientation may focus on the hedonic aspects of imported products and associate a positive country image with the quality of hedonic products to a greater extent. Hence,

\section{H1: Collectivistic (individualistic) consumers have a stronger positive influence of COO} image on a) evaluation; and b) behavioral intentions for utilitarian (hedonic) products. Long-term orientation is the extent to which a society exhibits a pragmatic, futureoriented perspective rather than a conventional historic or short-term perspective (Hofstede, 2001). Consumers with long-term orientation tend to prefer well-known national and global brands because they may be interested in forming a long-term relationship with these brands; 
whereas short-term oriented consumers prefer private labels because they may look for the shortterm and immediate benefit of lower prices (de Mooij and Hofstede, 2002). Long-term oriented consumers are also more financially responsible, as evident from their lower usage of credit cards and higher savings rates; and more loyal and innovative (Soares et al., 2007).

Prior research on hedonic vs. utilitarian choices shows that hedonic products encourage instant gratification and time-discounting (also known as temporally inconsistent preferences), wherein consumers are willing to forego long-term benefits for short-term pleasure of consuming a hedonic product (Wertenbroch, 1998). Hence, consumption of hedonic goods is more difficult to justify than utilitarian goods; resulting in greater association of guilt and regret with purchase of hedonic goods (Dhar and Wertenbroch, 2000).

Long-term oriented consumers may prefer buying imported utilitarian products, in order to maintain a rational self-perception and perceived long-term benefits. They may also be able to resist the temptations of buying imported hedonic products because of their greater self-control. In contrast, short-term oriented consumers may prefer buying imported hedonic products to enjoy the fun and excitement provided by these products, as they may not be concerned about maintaining a rational self-perception and may also have lower self-control.

H2: Long (short) term oriented consumers have a stronger positive influence of COO image on a) evaluation; and b) behavioral intentions for utilitarian (hedonic) products.

\section{Consumption Context (CC) - Private vs. Public}

Consumer purchase and use products in order to convey an image to themselves and others (Belk, 1988); they also tend to conform more to those decisions that they expect others to evaluate favorably (Ratner and Kahn, 2002). Individuals adhere more to social norms about what constitutes appropriate behavior when they are identifiable (public) compared to when they are 
anonymous (private) (Kulviwat et al., 2008). In other words, consumers' expectations about how others would evaluate their decisions have a stronger influence in public vs. private consumption context (Ratner and Kahn, 2002; Ariely and Levav, 2000; Choi et al., 2006). Similarly, attitudes about the public/private character of a product category also affect the degree to which normative factors influence consumption behaviors (Bearden and Etzel, 1982; Fisher and Price, 1992). Hence, the degree to which a consumer believes that consumption of a product is socially visible seems to increase the effect of social influence on purchase intentions (Graeff, 1996).

Studies show a stronger $\mathrm{COO}$ effect in a collectivistic culture (i.e., China) when the same product (Wine) is meant for public versus private consumption (e.g., Hu et al., 2008). However, others find no significant effect of $\mathrm{COO}$ on conspicuous consumption, and no significant difference in the $\mathrm{COO}$ effects on products meant for private vs. public consumption, in a similar cultural context (i.e., an East Asian capital city) (Piron, 2000). Hence, there is no consensus on the cross-cultural differences in the COO effects based on consumption context.

Cultures with high power distance highlight the importance of 'Face', which refers to social and professional position, reputation, and self image (Hofstede, 2001). In these cultures, face is very important and loss of face may have disastrous personal consequences. As a result, people in such cultures are always under strong social pressure to meet the expectation of others in order to maintain face (Hu et al., 2008). Most collectivistic cultures have evolved from feudal societies, which determine one's position in the social hierarchy through the concept of face. Under such an environment, buying and possessing expensive imported products helps the individuals gain face and social status by demonstrating economic success. In fact, such a tendency is likely to be particularly strong for those products consumed or used in public due to their greater visibility compared to products used in private (Belk, 1999). Therefore, 
H3: Consumers with high (low) power distance have a stronger positive influence of COO image on a) evaluation; and b) behavioral intentions for public (private) products. Masculinity-femininity cultural orientation affects a person's self-concept; masculinity represents a preference for achievement, assertiveness, and material success; whereas femininity relates with a preference for relationships, modesty, caring for others, and the quality of life (Hofstede, 2001). High masculinity associates with the dominance of self-ego and status cues resulting in prevalence of symbolic consumption (de Mooij and Hofstede, 2002), and preference for emotional and hedonic appeals (Tsikriktsis, 2002). Hence, consumers with high masculine cultural orientation are more likely to use the purchase of imported luxury products and conspicuous consumption as a proxy for success and a symbolic means to demonstrate their achievements (Steenkamp et al., 1999). In contrast, consumers with feminine cultural orientation do not have a strong need to consume such products to display their status. Hence, the following:

H4: Masculine (feminine) consumers have a stronger positive influence of COO image on a) evaluation; and b) behavioral intentions for public (private) products.

\section{Product Involvement (PI)}

Prior research defines involvement as the "general level of interest in the object or the centrality of the object to the person's ego-structure" (i.e., enduring or product involvement), or "an internal state variable that indicates the amount of arousal, interest, or drive evoked by a particular stimulus or situation" (i.e., situational or purchase decision involvement) (Mittal, 1989). It is a well-studied construct linked with many different contexts, such as advertisements, products, and purchase decisions (Zaichkowsky, 1985); and has many facets including perceived importance and perceived risk, symbolic value, and hedonic value (Laurent and Kapferer, 1985). 
The Elaboration Likelihood Model (ELM) used in persuasion research predicts that consumers adopt a central route under high involvement and a peripheral route under low involvement (Petty et al., 1983). Consumers exert the necessary cognitive effort to evaluate the information available to them under the central route; in contrast, they tend to use more salient and readily accessible cues under the peripheral route. Hence, under low involvement with the product category, consumers may rely more on COO image because it is a salient and accessible cue on which they can base a buying decision (Han, 1989; Maheswaran, 1994).

In other words, rather than being merely another cognitive cue, $\mathrm{COO}$ image may act as a "halo" or "summary" cue to signal overall product quality. Many studies show that COO image influences the evaluation of low involvement imported products (Gurhan-Canli and Maheswaran, 2000; Verlegh et al., 2005); and that involvement negatively moderates the influence of $\mathrm{COO}$ image on perceived quality, product evaluations, and behavioral intentions (Josiassen et al., 2008). However, others show that the impact of COO image may weaken in the presence of other extrinsic cues such as price and brand (Ahmed et al., 2004).

In contrast, some argue that consumers who are more involved with a product may seek, use, and give more attention to information about that product category while evaluating or making a choice (Celsi and Olson, 1988). Using this perspective, researchers argue that consumers may be more likely to use $\mathrm{COO}$ image as an informational cue besides other intrinsic and extrinsic attributes for high-involvement products (d'Astous and Ahmed, 1999). Others show that situational involvement moderates the $\mathrm{COO}$ effects on product evaluations, and the pre-existing enduring involvement magnifies the effect of situational involvement (Lee et al., 2005). However, most of this research ignores the effects of culture and differences in product categories on the influence of involvement on consumers' evaluation of imported products. 
Despite some evidence to support the influence of culture on involvement, the relationship between culture and involvement remains largely unexplored (Coulter et al., 2003). Recent research shows that uncertainty avoidance positively moderates the relationships between risk involvement and situational involvement, and situational involvement and brand commitment; and negatively moderates the link between situational involvement and brand experimentation (Broderick, 2007). Uncertainty avoidance represents the degree to which members of a national culture feel uncomfortable with uncertainty and ambiguity, and look for ways to reduce these (Hofstede, 2001). In high uncertainty avoidance cultures, individuals prefer to maintain clarity and stick to the status quo, in comparison to low uncertainty avoidance cultures where individuals are more likely to challenge their belief system with new ideas and innovative behaviors (de Mooij and Hofstede, 2002).

In other words, individuals with high uncertainty avoidance orientation are less likely to take risks under high involvement situations. Hence, in the context of imported products, consumers with high uncertainly avoidance may be less likely to prefer and purchase high involvement imported products because of the greater risk associated with such products. However, consumers with low uncertainty avoidance have greater tolerance for ambiguity and risk appetite, and they would not mind buying imported products even in high involvement product categories. Therefore, the following hypothesis:

H5: Consumers with high (low) uncertainty avoidance have a stronger positive influence of COO image on a) evaluation; and b) behavioral intentions for low (high) involvement products. 
Table 1 summarizes all these hypotheses. Next, this paper describes a large-scale webbased study conducted to test all these hypotheses with consumers from four countries (China, India, UK, and USA) for eight products with different product characteristics.

$<$ Take in Table 1 about here $>$

\section{METHOD}

\section{Sample}

This study recruited employees of a large multinational firm from its offices in four countries (UK, China, India, and USA). The company is not especially associated with any of these four countries; hence any favorable attitudes towards a particular country may not lead to a bias. The corporate office sent an email to only the local employees (about 10000) in these four countries with a URL link to a web-based survey. Local employees were defined as those born in the home country, recruited locally, and who had spent most of their life in the home country. Thus, the survey excludes all the expats and non-local employees, and even those local born employees who had spent one year or more studying or living overseas.

Each URL link contained a unique password to prevent the employees from filling up more than one survey. To improve the response rate, the author entered the names of all the participants in a lucky draw with one hundred gift vouchers worth about US\$ 50 each as prizes. However, the names were not linked to the questionnaires and the survey was hosted on an independent website, to ensure complete anonymity of the responses and to minimize the possibility of demand characteristics and social desirability bias.

1568 participants completed the questionnaire (response rate $\sim 15.7 \%$, which appears to be quite high for web-based survey research). The web-based program also kept track of the time of submission for each questionnaire, which helped the author estimate the non-response bias. 
Specifically, he used this information to divide the participants into two groups (early vs. late responders) and compared their average scores for all the independent and dependent variables. There is no significant difference in these scores; suggesting that non-response bias may not be a major concern (Armstrong and Overton, 1977).

The author chose these four countries for several reasons. First, they represent significant differences in national cultural dimensions (Hofstede, 2001). China represents low individualism coupled with moderate uncertainty avoidance and masculinity, long-term orientation, and high power distance; whereas India is also high on power distance but moderate on the other dimensions. In contrast, UK and USA are both high on individualism and masculinity, and lower on the other dimensions. Second, China and India are large emerging markets; whereas UK and USA are two of the most developed markets; hence this study is able to control the effect of economic development on the $\mathrm{COO}$ effects. Third, prior research has validated the measures for all the constructs included in this study in all these countries showing significant variance in their average scores. Hence, these four countries provide a suitable setting to test all the hypotheses in this study. Table 2 shows the sample composition.

$<$ Take in Table 2 about here $>$

This study uses the employees of a single firm in the four countries as participants and the same web-based procedure to collect data from all of them, to control various confounding variables that plague survey-based cross-cultural studies with convenience samples (Hult et al., 2008). Thus, by using the same sampling frame it minimizes the between-group differences on non-focal variables; and also allows the comparison of focal relationships across the four country samples by ensuring significant variance within each country sample. Despite this, the samples from the four countries may not match exactly with each other; hence, the author included 
several demographic variables as covariates in the data analysis to further control any betweengroups differences. Moreover, the participants belong to a cross-section of urban consumers in these four countries with a wide range of socio-economic characteristics, hence the results for each sample may also generalize to the urban population in the respective countries.

\section{Procedure}

This study examines COO effects across eight electrical/electronic products meant for personal use (Table 3). The author chose a single product category to control for the possible confounding effects of inter-category factors such as between food products and personal accessories. The author identified these products based on a pre-test of more than fifty products with a sample of undergraduate students and adult shoppers $(\mathrm{N}=75)$. The participants classified each product into one of the eight categories using three product characteristics (PT, CC, and PI). For example, a DVD is a low involvement, hedonic product used in private; whereas a laptop computer is a high involvement, utilitarian product mostly used in public.

$<$ Take in Table 3 about here $>$

The study uses a two-part web-based questionnaire. The first part lists the eight products included in this study in a counterbalanced order and asks the participants to choose two categories in which they use an imported product. For both the products, the questionnaire collects product-related information including the product type (PT), consumption context (CC), product involvement $(\mathrm{PI})$, country-of-origin $(\mathrm{COO})$, product evaluation $(\mathrm{PE})$, and behavioral intentions (BI). The second part measures the six personal cultural orientations, the COO image (COI) for the countries-of-origin of both the imported products mentioned by each participant, and demographic characteristics (age, gender, education, income). 
The author developed a basic version of the questionnaire in English and pre-tested it with undergraduate students and adult shoppers $(\mathrm{N}=80)$. Based on the findings, the author altered some items slightly to improve their comprehension (shown in bold in Table 3). Next, the author took the help of a Chinese and an Indian student to translate the questionnaire into Mandarin and Hindi (the national languages of China and India respectively); and another pair of Chinese and Indian graduate students translated these back into English. The author compared the original English questionnaire with the back-translated versions, and found a few minor differences. He discussed and resolved these differences with the translators to develop the final versions.

\section{Measures}

Prior research shows little success in measuring Hofstede's (1994) cultural dimensions using his 20-item Value Survey Module (VSM) with individual consumers (e.g., Bearden et al., 2006). Others find the 26-item CVSCALE (Donthu and Yoo, 1998) quite reliable (Yoo and Donthu, 2005; Patterson et al., 2006; Soares et al., 2007). However, the CVSCALE only measures COL and assumes IND to be its opposite; whereas these two are independent cultural dimensions and should be measured separately (Oyserman et al., 2002). The Horizontal-Vertical Individualism-Collectivism (HVIC) scale operationalizes IND-COL and PDI as separate but inter-related dimensions (Triandis and Gelfand, 1998). HVIC scale shows high discriminant validity for IND-COL but not the horizontal-vertical dimension (Li and Aksoy, 2007). Hence, this study uses the HVIC scale to measure IND-COL, CVSCALE for other cultural orientations, and other scales to measure hedonic vs. utilitarian product type (Dhar and Wertenbroch, 2000), public vs. private consumption context, product involvement (Zaichkowsky, 1985), product evaluation (Lim et al., 1994), and COO image (Josiassen et al., 2008). 
This study measures the independent and dependent variables in the same questionnaire; hence it may suffer from common method variance (CMV). To minimize this problem, the author used several remedies as recommended by Podsakoff et al. (2003). Specifically, this study uses a web-based survey to reduce the possibility of socially desirable responding and evaluation apprehension by ensuring the anonymity of the responses, and also controls for the order bias and demand characteristics by counterbalancing the order of the measurement of the predictor and criterion variables. Half the participants completed the product-related information first followed by the personal information; whereas the other half completed these in reverse order.

A dummy variable (ORD, coded 0 and 1 for the two orders of questionnaire presentation) included as a covariate in data analysis does not show a significant influence, hence order bias and demand effects do not seem to be a major problem in this study. The participants also completed a series of filler tasks unrelated to this study between the two parts of the questionnaire, creating a psychological separation between the measurement of independent and dependent variables, and helps minimize CMV (Fulmer et al., 2009, p. 696). Finally, this study also uses scales with different response formats (e.g., Likert for independent variables and Semantic Differential for dependent variables), thus reducing the "method bias caused by the commonalities in scale endpoints and anchoring effects" (Podsakoff et al., 2003).

\section{DATA ANALYSIS AND FINDINGS}

\section{Measurement Invariance}

Since this study uses data collected from four different countries, the author uses Confirmatory Factor Analysis to validate their factor structure and establish their measurement equivalence across the four samples, with a Structural Equation Modeling (SEM) approach using Maximum Likelihood Estimation (MLE) procedure on AMOS 6.0. Specifically, he compared 
three unconstrained alternate measurement models - first, with all the items loading on a single factor; second, with five factors (IND and COL as one factor), and third, with the six factors (IND and COL as two factors, as hypothesized), across the four groups based on the participants' home countries (India, China, the UK, and USA).

The six factor model provides the best fit with a significantly lower $\chi^{2}$ value $(1861.79, d f$ $=1340)$ compared to the one factor $\left(\Delta \chi^{2}=1474.63, \Delta d f=75, \mathrm{p}<.001\right)$ and five factor $\left(\Delta \chi^{2}=\right.$ 608.40, $d f=23, \mathrm{p}<.001)$ models. All the other fit indices for the six factor model $\left(\chi^{2} / d f=1.39\right.$, $\mathrm{RMSEA}=.023, \mathrm{SRMR}=.058, \mathrm{CFI}=.97)$ are also better than the cut-off values $(\mathrm{RMSEA}<.06$, SRMR $<.08, \mathrm{CFI}>.95)$ recommended by Hu and Bentler $(1999)$ and $\left(1<\chi^{2} / d f<3\right)$ suggested by Wheaton et al. (1977). Tables 4 and 5 show the psychometric properties of all the scales.

$<$ Take in Table $4 \& 5$ about here $>$

A closer look at the output shows that all the parameter estimates $(\lambda)$ are significantly different from zero at the 5\% level, suggesting a high degree of convergent validity; and none of the confidence intervals of the correlation coefficients for each pair of scales ( $\Phi$ estimates) includes 1.0, thus supporting the discriminant validity of the three scales (Anderson and Gerbing, 1988). An additional test of discriminant validity involves constraining the estimated correlation parameter among the six factors to 1.0 and then performing a chi-square difference test on the values obtained in the constrained and unconstrained models. The $\chi^{2}$ value for the unconstrained model $(1861.79, d f=1340)$ is significantly lower than the constrained model $\left(\Delta \chi^{2}=984.35, \Delta d f\right.$ $=60, \mathrm{p}<.001)$, hence the different factors are not perfectly correlated (Anderson and Gerbing, 1988). Finally, the squared multiple correlations $\left(r^{2}\right)$ for all the scale items are above .40 , the average variance extracted ranges from .65 to .75 ; and the construct reliabilities range from .75 
to .85; hence all the constructs appear to be reliable (Bagozzi and Yi, 1988). Table 6 shows the correlation matrix for all the variables.

$<$ Take in Table 6 about here $>$

Based on the above, the six factor measurement model shows configural invariance across the four samples (Steenkamp and Baumgartner, 1998). However, despite configural invariance, the item measurements may not be equivalent across the two groups due to differences in the interpretation and/or endorsement of the items by the participants. Hence, the author tested for metric invariance next by constraining the matrix of factor loadings invariant across the two groups and compared the fit statistics with the unconstrained model (Steenkamp and Baumgartner, 1998). The $\chi^{2}$ value for the constrained model $(2023.97, d f=1436)$ was significantly higher than the configural model $\left(\Delta \chi^{2}=162.18, \Delta d f=96, \mathrm{p}<.01\right)$, and the other fit indices $(\mathrm{RMSEA}=.065, \mathrm{SRMR}=.087, \mathrm{CFI}=.92)$ were also poorer than the recommended cutoff values (Hu and Bentler, 1999).

These results do not support full metric invariance, hence the author explored partial metric invariance by examining the probability level of the equality constraints using the Lagrange Multiplier (LM) test, to identify the parameters that would significantly decrease the $\chi^{2}$ value if they were freely estimated subsequently (Byrne, 1994). A look at the LM $\chi^{2}$ values shows four constraints untenable with significantly different factor loadings across the four groups (for items \#12, 17, 25, and 27) as shown in Table 4. Releasing the equality constraints for these four items resulted in a $\chi^{2}$ value $(1972.51, d f=1420)$ higher than the configural model, but the difference was not significant $\left(\Delta \chi^{2}=110.72, \Delta d f=80, \mathrm{p}>.01\right)$. The other fit indices $\left(\chi^{2} / d f=\right.$ $1.39, \mathrm{RMSEA}=.043, \mathrm{SRMR}=.069, \mathrm{CFI}=.96)$ are also better than the recommended cut-off values, thus supporting partial metric invariance (Steenkamp and Baumgartner, 1998). 
Next, the author constrained the intercepts of the invariant items across the four groups to test scalar invariance, which allows comparison of the average scores for each items across the groups (Steenkamp and Baumgartner, 1998). For this constrained model the $\chi^{2}$ value $(2293.86, d f$ $\left.=1484, \chi^{2} / d f=1.55\right)$ was significantly higher than the partial metric invariance model $\left(\Delta \chi^{2}=\right.$ $321.35, \Delta d f=64, \mathrm{p}<.001) ;$ and the other fit indices $(\mathrm{RMSEA}=.072, \mathrm{SRMR}=.098, \mathrm{CFI}=.91)$ also suggest a poor fit (Hu and Bentler, 1999). These results do not support full scalar invariance.

A look at the $\operatorname{LM} \chi^{2}$ values shows six intercepts with untenable constraints and after relaxing these two constraints (for items $\# 2,7,13,15,22$ and 26), the revised model shows a $\operatorname{good}$ fit $\left(\chi^{2}=2035.24, d f=1460, \chi^{2} / d f=1.39, \mathrm{RMSEA}=.052, \mathrm{SRMR}=.073, \mathrm{CFI}=.95\right)$ with no significant difference in $\chi^{2}$ value with the partial metric invariance model $\left(\Delta \chi^{2}=62.73, \Delta d f=\right.$ 40, $\mathrm{p}>.01$ ), supporting partial scalar invariance (Steenkamp and Baumgartner, 1998).

Having achieved full configural and partial metric and scalar invariance, the author did not proceed with the remaining tests of invariance (factor covariance, factor variance and error variance), as the objectives of this study do not include exploring the differences in the association among the six factors across the four groups. Table 7 shows the results of the stepwise process for measurement invariance.

$<$ Take in Table 7 about here $>$

\section{Product Characteristics}

This study verified the classification of the eight products based on the three product characteristics (PT, CC, and PI) using a pre-test, however it also measures these characteristics as perceived by each participant, to control for any individual differences. Comparison of the average scores for all these characteristics supports the a-priori classification, as shown in Table 
8. Hence, the author uses the dummy variables to operationalize these characteristics, namely PT $(0=$ Utilitarian, $1=$ Hedonic $), \mathrm{CC}(0=$ Private, $1=$ Public $)$, and PI $(0=$ low, $1=$ high $)$.

$<$ Take in Table 8 about here $>$

\section{Hypotheses Testing}

Testing all the hypotheses in this study requires a test of significance in the interaction between the cultural factors (IND, COL, PDI, UAI, MAS, and LTO) and product characteristics (PT, CC, and PI) in their influence on the association of COO image (COI) with product evaluation (PE) and behavioral intentions (BI). Hence, the author uses Moderated Multiple Regression (MMR) method with the mean-centered scores for the six cultural factors, three product characteristics, COI, and their interaction terms as the predictors for PE and BI, the two dependent variables (Baron and Kenny, 1986). Table 9 shows the regression analysis output.

$<$ Take in Table 9 about here $>$

None of the covariates have a significant influence including the dummy variables ORD (order of questionnaire presentation) and the four demographic characteristics (age, gender, education and occupation), as seen in their non-significant regression coefficients in Table 9. Hence, this paper excludes these variables from further analyses. Moreover, having achieved measurement variance, the author pooled the data from the four countries for data analysis.

Both the regression models provided good fit to the data for $\mathrm{PE}\left(\operatorname{adj} . \mathrm{R}^{2}=.32, F=19.87\right.$, $p<.001)$ and BI $\left(\operatorname{adj} . \mathrm{R}^{2}=.28, F=16.32, p<.001\right)$ with most standardized beta coefficients statistically significant and in expected directions. Specifically, COO has a significant positive effect on $\operatorname{PE}(\beta=.34, p<.001)$ and $\mathrm{BI}(\beta=.27, p<.001)$ showing that consumers have more favorable perceptions about products imported from countries with higher image compared to others. Among the six cultural orientations, PDI has a positive effect on both $\mathrm{PE}(\beta=.12, p<$ 
$.01)$ and $\mathrm{BI}(\beta=.15, p<.01)$ and UAI has a negative effect on $\mathrm{PE}(\beta=-.13, p<.01)$ and $\mathrm{BI}(\beta=$ $-.18, p<.01)$; whereas the other four cultural orientations do not have a significant effect.

Similarly, among the three product characteristics, product type has a significant influence on PE $(\beta=.14, p<.01)$; consumption context influences both $\mathrm{PE}(\beta=.19, p<.01)$ and $\mathrm{BI}(\beta=.15, p<$ $.01)$; whereas product involvement has no significant direct effect on either PE or BI.

The interaction term IND X COI X PT is significant and positive for both $\mathrm{PE}(\beta=.19, p$ $<.001)$ and BI $(\beta=.12, p<.01)$, hence IND has a stronger positive influence on the relationship of $\mathrm{COI}$ with $\mathrm{PE}$ and $\mathrm{BI}$ for hedonic vs. utilitarian products. In contrast, the interaction term $\mathrm{COL}$ $\mathrm{X}$ COI X PT is significant and negative for both $\mathrm{PE}(\beta=-.17, p<.001)$ and $\mathrm{BI}(\beta=-.11, p<$ $.01)$, hence COL has a stronger negative influence on the relationship of COI with PE and BI for hedonic vs. utilitarian products. These findings support hypothesis 1a and 1b. Similarly, the interaction term LTO X COI X PT is significant and negative for both $\mathrm{PE}(\beta=-.22, p<.001)$ and BI $(\beta=-.12, p<.01)$, hence LTO has a stronger negative influence on the relationship of COI with PE and BI for hedonic vs. utilitarian products, supporting hypothesis $2 \mathrm{a}$ and $2 \mathrm{~b}$.

The interaction term PDI X COI X CC is significant and positive for both $\mathrm{PE}(\beta=.24, p$ $<.001)$ and $\mathrm{BI}(\beta=.17, p<.01)$, hence PDI has a stronger positive influence on the relationship of COI with PE and BI for public vs. private products, supporting hypothesis $3 \mathrm{a}$ and $3 \mathrm{~b}$. The interaction term MAS X COI X CC is significant and positive for both $\mathrm{PE}(\beta=.13, p<.01)$ and $\mathrm{BI}(\beta=.18, p<.01)$, hence MAS has a stronger positive influence on the relationship of COI with PE and BI for public vs. private products, supporting hypothesis $4 \mathrm{a}$ and $4 \mathrm{~b}$. Finally, the interaction term UAI X COI X PI is significant and negative for both $\mathrm{PE}(\beta=-.22, p<.001)$ and $\mathrm{BI}(\beta=-.12, p<.01)$, hence UAI has a stronger negative influence on the relationship of COI with $\mathrm{PE}$ and $\mathrm{BI}$ for high vs. low involvement products, thus supporting hypothesis $5 \mathrm{a}$ and $5 \mathrm{~b}$. 


\section{DISCUSSION}

Prior research shows differences in the COO effects across different product categories, but do not account for any cultural differences (e.g., Roth and Romeo, 1992; Leonidou et al., 2007; Chryssochoidis et al., 2007; Kaynak and Cavusgil, 1983). Others explore cross-cultural differences in $\mathrm{COO}$ effects but focus on one or two cultural orientations such as individualismcollectivism (Gurhan-Canli and Maheswaran, 2000), and uncertainty avoidance (Lee et al., 2007). Hence, it is not clear how cultural orientations may influence COO effects across different product categories. This study extends prior research on the influence of culture and product characteristics on the $\mathrm{COO}$ effects, by hypothesizing interactions among six cultural orientations and three product characteristics and exploring these across eight product categories. In the process, it helps explain prior mixed findings and addresses some important research gaps.

First, previous studies show a stronger effect of COO image on hedonic vs. utilitarian products and in developed Western countries such as US and Germany vs. emerging markets such as Russia and China (Huddleston et al., 2000, 2001). This study reconciles these prior research findings by showing that $\mathrm{COO}$ effects are not uniform for consumers with different cultural orientations. Specifically, it shows that collectivistic and long-term oriented consumers have a stronger positive influence of $\mathrm{COO}$ image on their evaluation and behavioral intentions for utilitarian products; whereas individualistic and short-term oriented consumers have a stronger positive influence of COO image for hedonic products.

Second, recent studies show stronger positive effect of COO image on the products meant for public vs. private consumption among Chinese consumers (Hu et al., 2008); whereas others showed no such difference in a similar cultural context in East Asia (Piron, 2000). This research helps clarify prior findings by showing that consumers with high power distance (vertical) and 
masculine orientations have a stronger positive influence of $\mathrm{COO}$ image on their evaluation and behavioral intentions for public products; whereas consumers with low power distance (horizontal) and feminine orientations have a stronger positive influence for private products. Thus, by combining the consumption context with the cultural orientation, this research extends our understanding of the influence of culture on $\mathrm{COO}$ effects.

Third, most studies show a stronger positive influence of COO image for low vs. high involvement products (Chattalas et al., 2008; Josiassen et al., 2008; Gürhan-Canli and Maheswaran, 2000); whereas others show exactly the opposite results, with higher positive influence of COO image on high vs. low involvement products (Batra et al., 2000; Kinra, 2006; Lin and Chen, 2006). Interestingly, some show that the presence of other extrinsic cues may weaken the $\mathrm{COO}$ effects for low involvement products such as price and brand (Ahmed et al., 2004), or specific product attributes (Lee et al., 2005).

However, most of these studies ignore the influence of culture despite studying COO effects in different countries and cultural settings (Bhaskaran and Sukumaran, 2007). This study shows that the consumers with high uncertainty avoidance orientation have a stronger positive influence of COO image on their evaluation and behavioral intentions for low involvement products; whereas consumers with low uncertainty avoidance orientation have a stronger positive influence for high involvement products. Thus, it uses the interaction between involvement level and uncertainty avoidance to expand our knowledge about cultural differences in COO effects.

This research also has important managerial implications for international marketers. A better understanding of the differences in the influence of various cultural orientations on the COO effects based on different product characteristics would help companies better position their products and segment their target markets. This should allow them to direct their marketing 
activities and promotional inputs more effectively; and not only retain their existing consumers, but also gain market shares by attracting conversions from their competitors.

Specifically, this study shows that consumers with individualistic and short-term orientations tend to prefer imported hedonic products, whereas collectivists and long-term oriented consumers may prefer imported utilitarian products. Similarly, consumers with high power distance and masculine orientations prefer imported products for public consumption, whereas those with lower power distance and feminine orientations prefer imported products for private consumption. Finally, consumers with high uncertainty avoidance orientation rely more on $\mathrm{COO}$ image for low involvement products, compared to low uncertainty avoidance consumers who rely on it for high involvement products.

Based on the above, international marketers may highlight the hedonic elements of their products to attract the individualistic and short-term oriented consumers, and highlight the utilitarian aspects for the collectivistic and long-term oriented consumers. Similarly, it may be more useful for them to target consumers with high power distance and masculine orientations for public consumption products and those with lower power distance and feminine orientation for private consumption products. Finally, they may highlight the other extrinsic cues such as brand, price and product attributes for low involvement products, if they wish to downplay the importance of $\mathrm{COO}$ information, when targeting consumers with high uncertainty avoidance. Thus, multinational companies may incorporate these insights into their marketing plans and strategies to customize their product-mix and activities based on different cultural orientations and product characteristics in their diverse target markets. 


\section{LIMITATIONS AND DIRECTIONS FOR FUTURE RESEARCH}

This research provides some fresh insights into the well-researched COO effects, by exploring the interaction between cultural orientations and product characteristics; however it has some limitations that future research may address. First, this study uses a single product category (electrical/electronic products for personal use) with employees of a single company across four different countries. While this approach helps the author minimize the influence of various confounding variables and allows the comparison of focal relationships across different groups, the findings may not generalize to the overall populations in these four countries and other product categories. Hence, future research using other product categories and consumers from different countries with diverse socio-economic status may help generalize these findings.

Prior research argues against using $\mathrm{COO}$ as the only cue as it may inflate its importance and suggests using other intrinsic (taste, design, fit, and other product features) and extrinsic (price, brand, warranty and after-sales-service) cues (Ahmed and d'Astous, 2008; Josiassen et al., 2008; Bilkey and Nes, 1982). This study uses COO as the only cue but it may not be a problem because the objective of this study is to explore the interaction between cultural orientations and product characteristics on the influence of $\mathrm{COO}$ image and not to compare its importance against other cues (e.g., brand, price etc.). However, it would be useful to explore the differences in the importance attached to other cues besides COO for different groups of consumers based on their demographic, psychographic and socio-cultural factors, across different product categories.

Finally, future research may also explore the interaction among different cultural orientations (e.g., individualism and uncertainty avoidance, or collectivism and power distance) and product characteristics (e.g., product type and consumption context) to provide deeper insights into their influence on $\mathrm{COO}$ effects. 


\section{REFERENCES}

Ahmed, S. A. and d'Astous, A. 2008. Antecedents, moderators and dimensions of country-oforigin evaluations. International Marketing Review 25 (1):75-106.

Ahmed, S. A., d'Astous, A., and Eljabri, J. 2002. The impact of technological complexity on consumers' perceptions of products made in highly and newly industrialized countries. International Marketing Review 19 (4):387-407.

Ahmed, Z. U., Johnson, J. P., Xia, Y., Chen, K. F., Han, S. T., and Lim, C. B. 2004. Does country of origin matter for low-involvement products? International Marketing Review 21 (1):102-120.

Alden, D. L., Steenkamp, J.-B. E. M., and Batra, R. 2006. Consumer attitudes toward marketplace globalization: Structure, antecedents and consequences. International Journal of Research in Marketing 23 (3):227-239.

Almonte, J., Falk, C., Skaggs, R., and Cárdenas, M. 1995. Country-of-Origin Bias Among HighIncome Consumers in Mexico: An Empirical Study. Journal of International Consumer Marketing 8 (2):27-44.

Anderson, J. C. and Gerbing, D. W. 1988. Structural equation modeling in practice: A review and recommended two step approach. Psychological Bulletin 103 (May):411-423.

Ariely, D. and Levav, J. 2000. Sequential choice in group settings: Taking the road less traveled and less enjoyed. Journal of Consumer Research 27 (3):279-290.

Armstrong, J. S. and Overton, T. S. 1977. Estimating Non-response Bias in Mail Surveys. Journal of Marketing Research 14 (Aug):396-402.

Arnold, M. J. and Reynolds, K. E. 2003. Hedonic Shopping Motivations. Journal of Retailing 79:77-95.

Bagozzi, R. P. and Yi, Y. 1988. On the evaluation of structural equation models. Journal of the Academy of Marketing Sciences 16 (1):74- 84.

Balabanis, G. and Diamantopoulos, A. 2004. Domestic Country Bias, Country-of-Origin Effects, and Consumer Ethnocentrism: A Multidimensional Unfolding Approach. Journal of the Academy of Marketing Science 32 (1):80-95.

Baron, R. M. and Kenny, D. A. 1986. The Moderator-Mediator variable in social psychological research: Conceptual, strategic and statistical considerations. Journal of Personality and Social Psychology 51 (6):1173-1182.

Batra, R. 1997. Marketing issues and challenges in transitional economies. Journal of International Marketing 5 (4):95-114. 
Batra, R., Ramaswamy, V., Alden, D. L., Steenkamp, J.-B. E. M., and Ramachander, S. 2000. Effects of brand local and nonlocal origin on consumer attitudes in developing countries. Journal of Consumer Psychology 9 (2):83-95.

Bearden, W. O. and Etzel, M. J. 1982. Reference group influence on product and brand purchase decisions. Journal of Consumer Research 9 (3):183-194.

Bearden, W. O., Money, R. B., and Nevins, J. L. 2006. Multidimensional versus unidimensional measures in assessing national culture values: The Hofstede VSM 94 example. Journal of Business Research 59:195-203.

Belk, R. W. 1988. Possessions and the Extended Self. Journal of Consumer Research 15 (September):139-168.

1999. Leaping Luxuries and Transitional Consumers. In Marketing Issues in Transition Economies, edited by R. Batra. Boston, MA: Kluwer Academic Press.

Bhaskaran, S. and Sukumaran, N. 2007. Contextual and methodological issues in COO studies. Marketing Intelligence \& Planning 25 (1):66-81.

Bilkey, W. J. and Nes, E. 1982. Country-of-origin effects on product evaluations. Journal of International Business Studies 13 (1):89-99.

Broderick, A. J. 2007. A cross-national study of the individual and national-cultural nomological network of consumer involvement. Psychology \& Marketing 24 (4):343-374.

Byrne, B. M. 1994. Structural Equation Modeling with EQS and EQS/Windows: Basic concepts, applications, and programming. Newbury Park, CA: Sage.

Chattalas, M., Kramer, T., and Takada, H. 2008. The impact of national stereotypes on the country of origin effect; A conceptual framework. International Marketing Review 25 (1):54-74.

Choi, J., Kim, B. K., Choi, I., and Yi, Y. 2006. Variety-Seeking Tendency in Choice for Others: Interpersonal and Intrapersonal Causes. Journal of Consumer Research 32 (4):590-595.

Chryssochoidis, G., Krystallis, A., and Perreas, P. 2007. Ethnocentric beliefs and country-oforigin (COO) effect Impact of country, product and product attributes on Greek consumers' evaluation of food products. European Journal of Marketing 41 (11/12):2007.

Coulter, R. A., Price, L. L., and Feick, L. 2003. Rethinking the origins of involvement and brand commitment: Insights from postsocialist Central Europe. Journal of Consumer Research 30 (2):151-169.

Cui, G. and Liu, Q. 2001. Emerging market segments in a transitional economy: A study of urban consumers in China. Journal of International Marketing 9 (1):84-106. 
d'Astous, A. and Ahmed, S. A. 1999. The importance of country images in the formation of consumer product perceptions. International Marketing Review 16 (2):108-126.

de Mooij, M. K. and Hofstede, G. 2002. Convergence and Divergence in Consumer behavior: Implications for International Retailing. Journal of Retailing 78 (1):61-69.

Dhar, R. and Wertenbroch, K. 2000. Consumer Choice Between Hedonic and Utilitarian Goods. Journal of Marketing Research 37 (February):60-71.

Donthu, N. and Yoo, B. 1998. Cultural influences on service quality expectations. Journal of Service Research 1 (2):178-86.

Douglas, S. P. and Craig, C. S. 1997. The Changing Dynamic of Consumer Behavior: Implications for Cross-Cultural Research. International Journal of Research in Marketing 14 (4):379-395.

Fisher, R. J. and Price, L. 1992. An investigation into the social context of early adoption behavior. Journal of Consumer Research 19 (3):477-487.

Fulmer, I. S., Barry, B., and Long, D. A. 2009. Lying and Smiling: Informational and Emotional Deception in Negotiation. Journal of Business Ethics 88 (4):691-709.

Graeff, T. R. 1996. Image Congruence Effects on Product Evaluations: The Role of SelfMonitoring and Public/Private Consumption. Psychology \& Marketing 13 (5):481-499.

Gurhan-Canli, Z. and Maheswaran, D. 2000. Cultural variations in country of origin effects. Journal of Marketing Research 37 (August):309-317.

Gürhan-Canli, Z. and Maheswaran, D. 2000. Cultural variations in country of origin effects. Journal of Marketing Research 37 (August):309-317.

- 2000. Determinants of country-of-origin evaluations. Journal of Consumer Research 27:96-108.

Han, C. M. 1989. Country Image: Halo or Summary Construct? Journal of Marketing Research 26:222-229.

Häubl, G. and Elrod, T. 1999. The impact of congruity between brand name and country of production on consumers' product quality judgments. International Journal of Research in Marketing 16 (3):199-215.

Hirschman, E. C. 1986. The effect of verbal and pictorial advertising stimuli on aesthetic, utilitarian and familiarity perceptions. Journal of Advertising 15 (Summer):27-34.

Hofstede, G. 1994. Value Survey Module 1994 Manual. Maastricht, The Netherlands: IRIC, University of Tilburg. 
2001. Culture's consequences: comparing values, behaviors, institutions, and organizations across nations. 2nd ed. Thousand Oaks, CA: Sage Publications.

Holbrook, M. B. and Hirschman, E. C. 1982. The Experiential Aspects of Consumption: Consumer Fantasies, Feelings, and Fun. Journal of Consumer Research 9 (September):132-140.

Holbrook, M. B. and Moore, W. L. 1981. Feature interactions in consumer judgments of verbal versus pictorial representation. Journal of Consumer Research 8:103-113.

Holt, D. B. 1995. How Consumers Consume: A Typology of Consumption Practices. Journal of Consumer Research 22 (June):1-16.

Hong, S. T. and Wyer, R. S. 1989. Effects of country-of-origin and product attribute information on product evaluation: An information processing perspective. Journal of Consumer Research 16 (2):175-187.

1990. Determinants of Product Evaluation: Effects of the Time Interval Between Knowledge of a Product's Country of Origin and Information About Its Specific Attributes. Journal of Consumer Research 17 (3):277-288.

Hu, L.-t. and Bentler, P. M. 1999. Cutoff criteria for fit indexes in covariance structure analysis: conventional criteria versus new alternatives. Structural Equation Modeling 6 (1):1-55.

Hu, X., Li, L., Xie, C., and Zhou, J. 2008. The effects of country-of-origin on Chinese consumers' wine purchasing behaviour. Journal of Technology Management in China 3 (3):292-306.

Huddleston, P., Good, L. K., and Stoel, L. 2000. Consumer ethnocentrism, product necessity and quality perceptions of Russian consumers. The International Review of Retail, Distribution and Consumer Research 10 (2):167-181.

2001. Consumer ethnocentrism, product necessity and Polish consumers' perceptions of quality. International Journal of Retail \& Distribution Management 29 (5):236-246.

Hult, G. T. M., Ketchen Jr., D. J., Griffith, D. A., Finnegan, C. A., Gonzalez-Padron, T., Harmancioglu, N., Huang, Y., Talay, M. B., and Cavusgil, S. T. 2008. Data equivalence in cross-cultural international business research. Journal of International Business Studies 39:1027-1044.

Johansson, J. K., Ronkainen, I. A., and Czinkota, M. R. 1994. Negative Country-of-Origin Effects: The Case of The New Russia. Journal of International Business Studies 25 (1):157-176.

Josiassen, A. and Harzing, A.-w. 2008. Descending from the ivory tower: reflections on the relevance and future of country-of-origin research. European Management Review 5 (4):264-270. 
Josiassen, A., Lukas, B. A., and Whitwell, G. J. 2008. Country-of-origin contingencies: Competing perspectives on product familiarity and product involvement. International Marketing Review 25 (4):423-440.

Kaynak, E. and Cavusgil, S. T. 1983. Consumer attitudes towards products of foreign origin: Do they vary across product classes. International Journal of Advertising 2:147-157.

Kinra, N. 2006. The effect of country-of-origin on foreign brand names in the Indian market. Marketing Intelligence \& Planning 24 (1):15-30.

Klein, J. G. 2002. Us versus them, or us versus everyone? Delineating consumer aversion to foreign goods. Journal of International Business Studies 33 (2):345-363.

Knight, G. A. and Calantone, R. J. 2000. A flexible model of consumer country-of-origin perceptions: A cross-cultural investigation. International Marketing Review 17 (2):127-.

Kulviwat, S., Bruner II, G. C., and Al-Shuridah, O. 2008. The role of social influence on adoption of high tech innovations: The moderating effect of public/private consumption. Journal of Business Research Forthcoming.

Laurent, G. and Kapferer, J.-N. 1985. Measuring Consumer Involvement Profiles. Journal of Marketing Research 22 (Feb):41-53.

Leclerc, F., Schmitt, B. H., and Dubé, L. 1994. Foreign Branding and Its Effects on Product Perceptions and Attitudes. Journal of Marketing Research 31 (May):263-270.

Lee, J. A., Garbarino, E., and Lerman, D. 2007. How cultural differences in uncertainty avoidance affect product perceptions. International Marketing Review 24 (3):330-349.

Lee, W.-N., Yun, T., and Lee, B.-K. 2005. The Role of Involvement in Country-of-Origin Effects on Product Evaluation: Situational and Enduring Involvement. Journal of International Consumer Marketing 17 (2/3):51-72.

Leonidou, L. C., Palihawadana, D., and Talias, M. A. 2007. British consumers' evaluations of US versus Chinese goods: A multi-level and multi-cue comparison. European Journal of Marketing 41 (7/8):786-820.

Levy, G. R. 1996. Consumer marketing in china: chasing billions, catching millions. Hong Kong: Economist Intelligence Unit.

Li, F. and Aksoy, L. 2007. Dimensionality of Individualism-Collectivism and Measurement Equivalence of Triandis and Gelfand's Scale. Journal of Business and Psychology 21 (3):313-329.

Lim, E. A. C. and Ang, S. H. 2008. Hedonic vs. utilitarian consumption: A cross-cultural perspective based on cultural conditioning. Journal of Business Research 61 (3):225-232. 
Lim, J. S., Darley, W. K., and Summers, J. O. 1994. An assessment of country of origin effects under alternative presentation formats. Journal of the Academy of Marketing Science 22 (3):274-282.

Lin, L.-Y. and Chen, C.-S. 2006. The influence of the country-of-origin image, product knowledge and product involvement on consumer purchase decisions: an empirical study of insurance and catering services in Taiwan. Journal of Consumer Marketing 23 (1):3442 .

Maheswaran, D. 1994. Country of origin as a stereotype: effects of consumer expertise and attribute strength on product evaluations. Journal of Consumer Research 21 (2):354-365.

Malhotra, N. K. and McCort, J. D. 2001. A cross-cultural comparison of behavioral intention models Theoretical consideration and an empirical investigation. International Marketing Review 18 (3):235-269.

Manrai, L. A., Lascu, D.-N., Manrai, A. K., and Babb, H. W. 2001. A cross-cultural comparison of style in Eastern European emerging markets. International Marketing Review 18 (3):270-285.

Mittal, B. 1989. Measuring purchase decision involvement. Psychology and Marketing 6 (2):147-162.

Oyserman, D., Coon, H. M., and Kemmelmeier, M. 2002. Rethinking individualism and collectivism: Evaluation of theoretical assumptions and meta-analyses. Psychological Bulletin 128 (1):3-72.

Papadopoulos, N., Heslop, L. A., and Bamossy, G. 1990. A comparative image analysis of domestic versus imported products. International Journal of Research in Marketing 7 (4):283-294.

Patterson, P. G., Cowley, E., and Prasongsukarn, K. 2006. Service failure recovery: the moderating impact of individual-level cultural value orientation on perceptions of justice. International Journal of Research in Marketing 23:263-277.

Petty, R. E., Cacioppo, J. T., and Schumann, D. 1983. Central and Peripheral Routes to Advertising Effectiveness: The Moderating Role of Involvement. Journal of Consumer Research 10 (September):135-146.

Piron, F. 2000. Consumers' perceptions of the country-of-origin effect on purchasing intentions of (in)conspicuous products. Journal of Consumer Marketing 17 (4):308.

Podsakoff, P. M., MacKenzie, S. B., Lee, J.-Y., and Podsakoff, N. P. 2003. Common Method Biases in Behavioral Research: A Critical Review of the Literature and Recommended Remedies. Journal of Applied Psychology 88 (5):879-903. 
Pollay, R. W., Tse, D. K., and Y., W. Z. 1990. Advertising propaganda and value change in economic development: the new cultural revolution in China and attitudes towards advertising. Journal of Business Research 20 (Mar):83-95.

Ratner, R. K. and Kahn, B. E. 2002. The impact of private versus public consumption on varietyseeking behavior. Journal of Consumer Research 29:246-257.

Roth, M. and Romeo, J. 1992. Matching product category and country image perceptions. Journal of International Business Studies 23 (3):477-497.

Russell, D. W. and Russell, C. A. 2006. Explicit and implicit catalysts of consumer resistance: The effects of animosity, cultural salience and country-of-origin on subsequent choice. International Journal of Research in Marketing 23 (3):321-331.

Schaefer, A. 1997. Consumer knowledge and country of origin effects. European Journal of Marketing 31 (1):56-72.

Schwartz, S. H., Melech, G., Lehmann, A., Burgess, S., Harris, M., and Owens, V. 2001. Extending the Cross-Cultural Validity of the Theory of Basic Human Values with a Different Method of Measurement. Journal of Cross-Cultural Psychology 32 (5):519542.

Sharma, P. 2009. Country-of-Origin Effects in Developed vs. Emerging Markets: Exploring the Contrasting Roles of Materialism and Value-Consciousness. Journal of International Business Studies Accepted for Publication (Forthcoming).

Shimp, T. A. and Sharma, S. 1987. Consumer ethnocentrism: Construction and validation of the CETSCALE. Journal of Marketing Research 24 (August):280-289.

Smith, W. R. 1993. Country-of-origin bias: a regional labeling solution. International Marketing Review 10 (6):4-12.

Soares, A. M., Farhangmehr, M., and Shoham, A. 2007. Hofstede's dimensions of culture in international marketing studies. Journal of Business Research 60 (4):277-284.

Steenkamp, J.-B. E. M. and Baumgartner, H. 1998. Assessing Measurement Invariance in CrossNational Consumer Research. Journal of Consumer Research 25 (1):78-90.

Steenkamp, J.-B. E. M., Hofstede, F. t., and Wedel, M. 1999. A Cross-National Investigation into the Individual and National Cultural Antecedents of Consumer Innovativeness. Journal of Marketing 63 (April):55-69.

Steenkamp, J.-B. E. M. and Ter Hofstede, F. 2002. International Market Segmentation: Issues and Perspectives. International Journal of Research in Marketing 19 (3):185-213.

Strizhakova, Y., Coulter, R. A., and Price, L. R. 2008. The Meanings of Branded Products: A Cross-National Scale Development and Meaning Assessment. International Journal of Research in Marketing 25 (2):82-93. 
Triandis, H. C. and Gelfand, M. J. 1998. Converging measurement of horizontal and vertical individualism and collectivism. Journal of Personality and Social Psychology 74 (1):118-128.

Tse, D. K. 1996. Understanding Chinese people as consumers: past findings and future propositions. In The handbook of Chinese psychology, edited by M. H. Bond. Hong Kong: Oxford University Press.

Tse, D. K., Belk, R. W., and Zhou, N. 1989. Becoming a consumer society: A longitudinal and cross-cultural content analysis of print ads from Hong Kong, the People's Republic of China, and Taiwan. Journal of Consumer Research 15 (March):457-472.

Tsikriktsis, N. 2002. Does culture influence web site quality expectations? An empirical study. Journal of Service Research 5 (2):101-113.

Usunier, J.-c. and Cestre, G. 2007. Product Ethnicity: Revisiting the Match Between Products and Countries. Journal of International Marketing 15 (3):32-72.

2008. Further considerations on the relevance of country-of-origin research. European Management Review 5 (4):271-274.

Verlegh, P. W. J. and Steenkamp, J.-B. E. M. 1999. A review and meta-analysis of country-oforigin research. Journal of Economic Psychology 20 (5):521-546.

Verlegh, P. W. J., Steenkamp, J.-B. E. M., and Meulenberg, M. T. G. 2005. Country-of-origin effects in consumer processing of advertising claims. International Journal of Research in Marketing 22 (2):127-139.

Wang, X. and Yang, Z. 2008. Does country-of-origin matter in the relationship between brand personality and purchase intention in emerging economies? Evidence from China's auto industry. International Marketing Review 25 (4):458-474.

Wertenbroch, K. 1998. Consumption Self-Control by Rationing Purchase Quantities of Virtue and Vice. Marketing Science 17 (Fall):317-337.

Wheaton, B., Muthen, B., Alwin, D. F., and Summers, G. F. 1977. Assessing reliability and stability in panel models. In Sociological methodology, edited by H. D. R. San Francisco: Jossey-Bass.

Yoo, B. and Donthu, N. 2005. The effect of personal cultural orientation on consumer ethnocentrism: Evaluations and behaviors of U.S. consumers toward Japanese products. Journal of International Consumer Marketing 18 (1-2):7-44.

Zaichkowsky, J. L. 1985. Measuring the Involvement Construct. Journal of Consumer Research 12 (December):341-352.

Zhou, L. and Hui, M. K. 2003. Symbolic value of foreign products in the People's Republic of China. Journal of International Marketing 11 (2):36-58. 
Table 1 - Hypotheses Summary

\begin{tabular}{|c|c|c|c|c|c|c|c|}
\hline \multirow[t]{2}{*}{ H\# } & \multirow{2}{*}{$\begin{array}{l}\text { Personal Cultural } \\
\text { Orientation }\end{array}$} & \multicolumn{2}{|c|}{ Product Type } & \multicolumn{2}{|c|}{$\begin{array}{c}\text { Consumption } \\
\text { Context }\end{array}$} & \multicolumn{2}{|c|}{$\begin{array}{c}\text { Product } \\
\text { Involvement }\end{array}$} \\
\hline & & Hedonic & Utilitarian & Private & Public & Low & High \\
\hline H1 & $\begin{array}{l}\text { Individualism } \\
\text { Collectivism }\end{array}$ & $\begin{array}{l}++ \\
+\end{array}$ & $\begin{array}{c}+ \\
++\end{array}$ & & & & \\
\hline $\mathrm{H} 2$ & $\begin{array}{l}\text { Long-term orientation } \\
\text { Short-term orientation }\end{array}$ & $\begin{array}{l}-- \\
++\end{array}$ & $\begin{array}{l}++ \\
+\end{array}$ & & & & \\
\hline H3 & $\begin{array}{l}\text { Low power distance } \\
\text { High power distance }\end{array}$ & & & $\begin{array}{l}++ \\
+\end{array}$ & $\begin{array}{l}-- \\
++\end{array}$ & & \\
\hline $\mathrm{H} 4$ & $\begin{array}{l}\text { Masculinity } \\
\text { Femininity }\end{array}$ & & & $\begin{array}{l}+ \\
-\end{array}$ & $\begin{array}{l}++ \\
--\end{array}$ & & \\
\hline H5 & $\begin{array}{l}\text { High uncertainty avoidance } \\
\text { Low uncertainty avoidance }\end{array}$ & & & & & $\begin{array}{l}++ \\
+\end{array}$ & $\begin{array}{l}-- \\
++\end{array}$ \\
\hline
\end{tabular}

Note: $++/--=$ strong positive / negative relationship; $+/-=$ weak positive / negative relationship.

Table 2 - Sample Composition

\begin{tabular}{lcccccccccc}
\hline \multirow{2}{*}{ Country } & \multirow{2}{*}{ Overall } & \multicolumn{2}{c}{ Gender } & \multicolumn{2}{c}{ Age } & \multicolumn{2}{c}{ Education } & \multicolumn{2}{c}{ Occupation } \\
\cline { 3 - 10 } & & Male & Female & $\leq \mathbf{3 0}$ yrs & $>\mathbf{3 0}$ yrs & $\begin{array}{c}\leq \text { High } \\
\text { School }\end{array}$ & $\begin{array}{c}>\text { High } \\
\text { School }\end{array}$ & $\begin{array}{c}\text { Blue } \\
\text { Collar }\end{array}$ & $\begin{array}{c}\text { White } \\
\text { Collar }\end{array}$ \\
\hline China & 310 & 167 & 143 & 163 & 147 & 151 & 159 & 154 & 156 \\
India & 348 & 198 & 150 & 182 & 166 & 172 & 176 & 165 & 183 \\
UK & 426 & 232 & 194 & 186 & 240 & 209 & 217 & 208 & 218 \\
USA & 484 & 256 & 228 & 246 & 238 & 234 & 250 & 245 & 239 \\
\hline & 1568 & 853 & 715 & 777 & 791 & 766 & 802 & 772 & 796 \\
\hline
\end{tabular}

Table 3 - Product Classification

\begin{tabular}{ccccc}
\hline & \multicolumn{2}{c}{ Low Involvement } & \multicolumn{2}{c}{ High Involvement } \\
& Hedonic & Utilitarian & Hedonic & Utilitarian \\
\hline \multirow{2}{*}{ Private } & DVD & $\begin{array}{c}\text { Battery } \\
\text { Charger }\end{array}$ & $\begin{array}{c}\text { Flat Screen } \\
\text { TV }\end{array}$ & $\begin{array}{c}\text { Desktop } \\
\text { Computer }\end{array}$ \\
& & Calculator & $\begin{array}{c}\text { Digital } \\
\text { Camera }\end{array}$ & Laptop \\
Public & MP3 player & Computer \\
\hline
\end{tabular}


Table 4 - Cultural Orientations Scales

Individualism (IND) $(1=$ Strongly disagree, $7=$ Strongly agree $)$

1. I would rather depend on myself than others.

2. My personal identity, independent of others, is very important to me. ${ }^{b}$

$\begin{array}{llll}.83 & .77 & .79 & .84\end{array}$

3. I rely on myself most of the time, rarely on others.

4. It is important that I do my job better than others.

.78

Collectivism (COL) $(1=$ Strongly disagree, $7=$ Strongly agree $)$

$\begin{array}{lllllll}\text { 5. The well-being of my group members (e.g., friends or colleagues) is important for me. } & .75 & .81 & .78 & .74\end{array}$

6. I feel good when I cooperate with my group members (e.g., friends or colleagues). $\quad \begin{array}{llll}.73 & .79 & .76 & .76\end{array}$

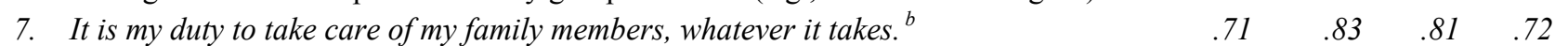

$\begin{array}{lllll}\text { 8. Family members should stick together, even if they do not agree. } & .71 & .77 & .75 & .74\end{array}$

$\underline{\text { Power Distance }(\mathbf{P D I})}(1=$ Strongly disagree, $7=$ Strongly agree $)$

People in higher positions should:

9. Make most decisions without consulting people in lower positions.

10. Not ask the opinions of people in lower positions too frequently.

11. Avoid social interaction with people in lower positions.

12. Not delegate important tasks to people in lower positions. ${ }^{a}$

13. Have more power than people in lower positions. ${ }^{b}$

$\begin{array}{llll}.74 & .75 & .73 & .72 \\ .72 & .74 & .76 & .74 \\ .71 & .77 & .79 & .70 \\ .69 & .75 & .78 & .63 \\ .61 & .74 & .78 & .68\end{array}$

Uncertainty Avoidance (UAI) $(1=$ Strongly disagree, $7=$ Strongly agree)

14. It is important to have detailed instructions to know what I need to do.

15. It is important for me to closely follow instructions and procedures. ${ }^{b}$

16. Rules and regulations are important because they tell me of what is expected of me.

17. I find standardized work procedures are helpful. ${ }^{a}$

18. I think instructions for operations are important.

Masculinity-Femininity (MAS) $(1=$ Strongly disagree, $7=$ Strongly agree $)$

19. It is more important for men to have a professional career than it is for women.

20. Men solve problems with logical analysis; women solve problems with intuition.

21. Solving difficult problems requires an aggressive approach, which is typical of men.

22. There are some jobs that a man can always do better than a woman. ${ }^{b}$

Long vs. Short-term Orientation (LTO) $(1=$ Strongly disagree, $7=$ Strongly agree)

23. Careful management of money (Thrift) is important for me.

$\begin{array}{llll}.75 & .79 & .81 & .78 \\ .74 & .77 & .78 & .75 \\ .77 & .82 & .84 & .71 \\ .76 & .75 & .74 & .73 \\ .69 & .77 & .73 & .61 \\ .72 & .76 & .74 & .75\end{array}$

24. I believe in going on resolutely in spite of opposition (Persistence).

25. Personal steadiness and stability is important for me. ${ }^{a}$

26. I always plan for the long-term. ${ }^{b}$

27. I am willing to give up today's fun for success in the future. ${ }^{a}$

28. Working hard today for success in the future is important for me.

Note: Words in bold represent changes in the original questionnaires based on the pre-test. Items in italics are not invariant ( ${ }^{\mathrm{a}}$ metric and ${ }^{\mathrm{b}}$ scalar) across the four groups and further data analyses exclude these items. 
Table 5 - Other Scales

Scale items

Product Type (PT)

I would describe this [product] as:

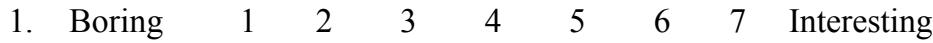



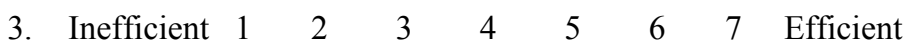

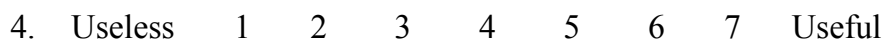

\section{Consumption Context (CC)}

I use this [product] most of the times:

5. At home $\begin{array}{lllllllll}1 & 2 & 3 & 4 & 5 & 6 & 7 & \text { Out of home }\end{array}$

6. Alone $\begin{array}{llllllll}1 & 2 & 3 & 4 & 5 & 6 & 7 & \text { With others }\end{array}$

7. In private $\begin{array}{llllllll}1 & 2 & 3 & 4 & 5 & 6 & 7 & \text { In public }\end{array}$

\section{Product Involvement (PI)}

I would describe this [product] as:

\begin{tabular}{|c|c|c|c|c|c|c|}
\hline Unimportant & 2 & 3 & 4 & 5 & 6 & 7 \\
\hline 9. Irrelevant & 2 & 3 & 4 & 5 & 6 & 7 \\
\hline 10. Worthless & 2 & 3 & 4 & 5 & 6 & 7 \\
\hline
\end{tabular}

COO Image (COI) $(1=$ Strongly disagree, $7=$ Strongly agree $)$

11. Products from [country] are a good purchase choice

12. Products from [country] are better than those from other countries

13. Products from [country] are of high quality

Product Evaluation (PE) $(1=$ Very bad, $7=$ Very good $)$

14. The overall quality of this [product] is

15. The overall performance of this [product] is

16. The value for money offered by this [product] is

Behavioral Intentions (BI) $(1=$ Very unlikely, $7=$ Very likely $)$

17. I would buy the same [product] again

18. I would recommend this [product] to others

19. I would continue using this [product] 
Table 6 - Correlation Matrix

\begin{tabular}{|c|c|c|c|c|c|c|}
\hline Independent Variables & $\mathbf{1}$ & 2 & 3 & 4 & 5 & 6 \\
\hline 1. Individualism & .78 & & & & & \\
\hline 2. Collectivism & $-.33^{* * *}$ & .75 & & & & \\
\hline 3. Power Distance & $-.21^{* * *}$ & $.24^{* * *}$ & .73 & & & \\
\hline 4. Uncertainty Avoidance & $.09^{* *}$ & $.14^{* * *}$ & $.07^{*}$ & .77 & & \\
\hline 5. Masculinity-Femininity & .05 & $.18^{* * *}$ & $.24^{* * *}$ & .03 & .72 & \\
\hline 6. Long-term orientation & $-.15^{* * *}$ & $.16^{* * *}$ & $.10^{* *}$ & $-.12^{* *}$ & .02 & .75 \\
\hline
\end{tabular}

Table 7 - Model Comparison for Measurement Invariance

\begin{tabular}{lcccccc}
\hline Model Description * & $\mathbf{X}^{2}$ & $\boldsymbol{d} f$ & $\chi^{2} / \boldsymbol{d} f$ & RMSEA & SRMR & CFI \\
\hline Full configural invariance & $\mathbf{8 7 1 . 1 9}$ & $\mathbf{5 2 8}$ & $\mathbf{1 . 6 5}$ & $\mathbf{. 0 4 3}$ & $\mathbf{. 0 5 8}$ & $\mathbf{. 9 7}$ \\
Full metric invariance & 1081.92 & 588 & 1.84 & .063 & .081 & .93 \\
Partial metric invariance & $\mathbf{9 2 5 . 8 4}$ & $\mathbf{5 6 8}$ & $\mathbf{1 . 6 3}$ & $\mathbf{. 0 5 3}$ & $\mathbf{. 0 6 7}$ & $\mathbf{. 9 5}$ \\
Full scalar invariance & 1227.59 & 620 & 1.98 & .065 & .083 & .93 \\
Partial scalar invariance & $\mathbf{9 9 1 . 4 2}$ & $\mathbf{6 1 2}$ & $\mathbf{1 . 6 2}$ & $\mathbf{. 0 5 4}$ & $\mathbf{. 0 7 1}$ & $\mathbf{. 9 5}$ \\
\hline
\end{tabular}

* Rows in bold show the supported invariance models.

Table 8 - Mean Comparison (Product Characteristics)

\begin{tabular}{|c|c|c|c|c|c|}
\hline \multirow[b]{2}{*}{ Products } & \multicolumn{2}{|c|}{$\underline{\text { Product Type }}$} & \multicolumn{2}{|c|}{$\frac{\text { Consumption }}{\underline{\text { Context }}}$} & \multirow{3}{*}{$\frac{\frac{\text { Product }}{\text { Involvement }}}{3.67}$} \\
\hline & \multirow{2}{*}{$\frac{\text { Hedonic }}{5.17^{* * *}}$} & \multirow{2}{*}{$\frac{\text { Utilitarian }}{3.23}$} & \multirow{2}{*}{$\frac{\text { Public }}{1.87}$} & \multirow{2}{*}{$\frac{\text { Private }}{5.84^{* * *}}$} & \\
\hline 1. DVD & & & & & \\
\hline 2. Battery Charger & 1.28 & $6.09^{* * *}$ & 1.45 & $5.76^{* * *}$ & 3.81 \\
\hline 3. MP3 Player & $5.21^{* * *}$ & 3.48 & $4.97^{* *}$ & 4.25 & 4.19 \\
\hline 4. Calculator & 1.33 & $5.24^{* * *}$ & $5.16^{* * *}$ & 4.43 & 3.93 \\
\hline 5. Flat Screen TV & $5.41^{* * *}$ & 4.59 & 4.39 & $5.68^{* * *}$ & $5.82^{* * *}$ \\
\hline 6. Desktop Computer & 4.78 & $5.32^{* *}$ & 1.19 & $5.93^{* * *}$ & $4.71^{* * *}$ \\
\hline 7. Digital Camera & 4.62 & $5.18^{* *}$ & $5.75^{* *}$ & 4.81 & $4.97^{* * * *}$ \\
\hline 8. Laptop Computer & 4.69 & $5.27^{* *}$ & $5.81^{* *}$ & 4.94 & $5.12^{* * *}$ \\
\hline
\end{tabular}


Table 9 - Moderated Multiple Regression Output

\begin{tabular}{|c|c|c|c|c|}
\hline \multirow{2}{*}{ Independent Variables } & \multicolumn{2}{|c|}{$\begin{array}{l}\text { PE (Product } \\
\text { evaluations) }\end{array}$} & \multicolumn{2}{|c|}{$\begin{array}{c}\text { BI (Behavioral } \\
\text { intentions) }\end{array}$} \\
\hline & $\begin{array}{c}\text { Std. Beta } \\
\text { Coefficients }\end{array}$ & t-values & $\begin{array}{c}\text { Std. Beta } \\
\text { Coefficients }\end{array}$ & t-values \\
\hline IND & .02 & .52 & .05 & .97 \\
\hline $\mathrm{COL}$ & .07 & 1.33 & .03 & .68 \\
\hline PDI & $.12^{* *}$ & 2.86 & $.15^{* *}$ & 3.29 \\
\hline UAI & $-.13^{* *}$ & -2.93 & $-.18^{* *}$ & -4.46 \\
\hline MAS & .09 & 1.62 & .06 & 1.23 \\
\hline LTO & .01 & .27 & .02 & .42 \\
\hline $\mathrm{COI}$ & $.34^{* * * *}$ & 7.89 & $.27^{* * *}$ & 6.75 \\
\hline PT (0=UTI, $1=$ HED) & $.14^{* *}$ & 3.13 & .08 & 1.66 \\
\hline $\mathrm{CC}(0=\mathrm{PVT}, 1=\mathrm{PUB})$ & $.19^{* *}$ & 4.82 & $.15^{* *}$ & 3.48 \\
\hline $\mathrm{PI}(0=\mathrm{LO}, 1=\mathrm{HI})$ & .03 & .65 & .01 & .26 \\
\hline IND X COI & .06 & 1.32 & .03 & .91 \\
\hline COL X COI & -.07 & -1.56 & $-.09^{*}$ & -1.98 \\
\hline LTO X COI & $-.11^{* *}$ & -2.34 & -.06 & -1.28 \\
\hline PDI X COI & $.12^{* *}$ & 2.79 & .07 & 1.65 \\
\hline MAS X COI & $.10^{*}$ & 2.03 & .08 & 1.89 \\
\hline UAI X COI & $-.09^{*}$ & -2.31 & $-.12^{* *}$ & -2.64 \\
\hline IND X COI X PT & $.19^{* * *}$ & 5.26 & $.12^{* *}$ & 2.91 \\
\hline COL X COI X PT & $-.17^{* *}$ & -3.69 & $-.11^{* *}$ & -2.57 \\
\hline LTO X COI X PT & $-.22^{* * *}$ & -5.53 & $-.12^{* *}$ & -2.85 \\
\hline PDI X COI X CC & $.24^{* *}$ & 5.94 & $.17^{* *}$ & 3.63 \\
\hline MAS X COI X CC & $.13^{* * *}$ & 2.93 & $.18^{* *}$ & 4.19 \\
\hline UAI X COI X PI & $-.18^{* *}$ & -4.27 & $-.21^{* * *}$ & -4.94 \\
\hline ORD & .03 & .63 & .01 & .37 \\
\hline AGE & .07 & 1.54 & .08 & 1.65 \\
\hline $\operatorname{GENDER}(0=\mathrm{F}, 1=\mathrm{M})$ & .01 & .35 & .05 & 1.18 \\
\hline EDUC & .06 & 1.37 & .03 & .65 \\
\hline $\operatorname{OCCUP}(0=\mathrm{B}, 1=\mathrm{W})$ & .08 & 1.63 & .07 & 1.49 \\
\hline Adj. $R^{2}$ (F-values) & \multicolumn{2}{|c|}{$.32\left(19.87^{* * * *}\right)$} & \multicolumn{2}{|c|}{$.28\left(16.32^{* * * *}\right)$} \\
\hline
\end{tabular}

